\title{
GROUND IMPROVEMENT AS ALTERNATIVE TO PILING - EFFECTIVE DESIGN SOLUTIONS FOR HEAVILY LOADED STRUCTURES
}

\author{
(Date received: 4.9.2019/Date accepted: 11.01.2020)
}

\author{
Sondermann, Wolfgang ${ }^{1}$ \\ ${ }^{1}$ Dr Ing., Consulting Engineer; Chairman German Geotechnical Society (DGGT), Essen, Germany
}

\begin{abstract}
Well-designed ground improvement options without compromising on stringent design criteria may effectively replace conventional foundation solutions for a wide range of applications involving heavy loads and structures sensitive to settlement. Case studies illustrate the application of different ground improvement methods used in different projects and soil conditions by adopting of advanced design considerations to achieve optimal solutions for the project and customers benefit. Beneficial returns in terms of lowering construction costs and shortening construction time with consistency in quality are discussed where applicable in relation to the required capabilities and experiences of an organisation to deliver the alternatives. Opportunity management gives the chance to achieve the project scopes for the client by optimizing cost, time and quality and recommendations are summarised to foster the chance to identify optimal geotechnical solutions.
\end{abstract}

\subsection{INTRODUCTION}

More and more civil structures are commissioned as economies around the world grow and the requirements for improved infrastructure accelerate. This inevitably leads to scarcity of land and demands to construct over soft ground, be it formed naturally or artificially. Nowadays, the subject of soft ground engineering attracts a lot of interest and it involves state-of-art engineering practices. Deep foundation using piling techniques is a frequently adopted foundation solution in such site. However, it may not be the only solution and often it is associated with relatively high cost as compared to other alternatives. In some occasions, deep foundation could even be an ineffective solution to adopt in soft ground. For a given scenario, there exists an optimal foundation solution that is technically sound, fit for its purpose and most economical. With rigorous design analysis and careful project execution, ground improvement also in combination with piles would be an efficient and more cost effective alternative to piled foundation only.

\subsection{BEST PRACTICE AND EVALUATION CRITERIA'S FOR OPTIMAL SOLUTIONS}

If ground is to be subjected to additional loads which exceed its previous load levels, the geotechnical design requirements have to be established to determin its suitability. Various codes and standards define the limit state conditions influenced by the ground:

- ultimate limit state design (position, design of load bearing members, total load bearing capacity of ground)

- serviceability limit state design (deformation, displacement),

- durability requirements of the products, materials used to construct

which have to be taken considered in the geotechnical design. If it is found, in the course of the geotechnical design, that the above limit state conditions are likely to occur when subjecting the ground to the planned loads, the following measures can be taken:

- unsuitable ground can be bypassed by certain construction measures,
- unsuitable ground can be removed and replaced by suitable ground,

- unsuitable ground can be made suitable using improvement measures.

When selecting the appropriate measures, in addition to taking into account the durability requirements, it is necessary, to determine the soil improvement requirements from the ultimate and serviceability state design in accordance with the geotechnical design categories. The general assessment criteria's for any ground improvement technology or method are:

- predictability of the technology as a reliable method

- repeatability of the process

- design-ability of the method in combination with the subsoil conditions

- operation as a controllable procedure (documented, monitored) to evaluate the achievements of the improvement technology as well as the limitations (Kirsch K., Sondermann W. 2003).

\subsection{GROUND IMPROVEMENT PROCEDURES}

As a general rule, the desired results of ground improvement are as follows:

- increase in density and shear strength, having a positive effect on all stability problems

- reduction of compressibility, which has a positive effect on deformability

- influencing permeability for the purpose of

- reducing water inflow/water outflow

- increasing deformation speed

- improving homogeneity

Many ground improvement techniques have been developed to treat soil particles to achieve better geotechnical properties. These techniques can be divided into the following categories (Sondermann W., Kirsch F. 2018):

Remove \& replace: it is perhaps the oldest and simplest 
technique. This method involves removing and / or replacing weak soil with better material which has suitable properties for the use. It is generally applied to relatively shallow depth (usually up to $2 \mathrm{~m}$ ). With more stringent environment protection regulations imposed by authorities, it has become more costly to dispose the weak soil in many countries, especially when the soil is contaminated with hazardous material.

Compaction/densification: this method improves soil properties by rearranging soil particles to denser state using mechanical means. Although surface compaction can be applied to many types of soils, deep compaction can only be effectively and economically used in cohesion-less soils.

Drainage/consolidation: soft soils are generally associated with high water content. Soil strength can be improved by forcing out the water. However, the process often takes a very long time in thick layer of cohesive soil due to low permeability and long drainage paths. To accelerate the process, drainage paths can be introduced. It is almost always used with surcharge, which preloads the soil to a higher degree of consolidation so it can carry intended loadings with little or no further consolidation.

Reinforcement: stiff elements can be introduced into weak soils to carry loads or redistribute loads so less loads are carried by the weak soils. Elements such as geotextile can also introduce tensile capacity into soil mass. Understanding the interactions and load transfer mechanism between stiffer elements and soil mass is vital in design.

Modification: soil properties can be completely changed by introduction of binding agents such as cement or lime. The modified soil would behave similar to very stiff to hard soils or even like low strength rock or concrete, depending on the soil and the amount of binding agent added.

Others: other ground improvement techniques such as ground freezing utilizes frozen water as binding agent to hold soil particles together, while electrical methods like electro-osmotic technique use electrical current to stabilise soil. These methods are less commonly used as compared to the other techniques.

The selection of the most suitable ground improvement method accompanied by the appropriate process sequences for any specific application must always be based on a thorough technical study and economic comparisons and references to the application limitations of the different methods.

\subsection{GEOTECHNICAL OPPORTUNITY MANAGEMENT}

In the context of holistic opportunity management, the project scope has to be achieved taking into account cost, time and quality (Ahmed, 2001). In general it is also necessary to weigh the advantages and disadvantages to exploit opportunities in the optimization process and enable the evaluation of potential conflicting tendencies in individual areas (quality optimization requiring costs and time increase versus cost optimization in conjunction with lower quality, etc.). This process is naturally highly dependent on the ability to recognise opportunities and the willingness to exploit them. Last but not least the expertise and experience available in the organisation play a decisive role to achieve optimal solutions considering the engineering and operational capabilities of the organisation (human factor) (Figure 1).

The contract shall be designed accordingly, so that all

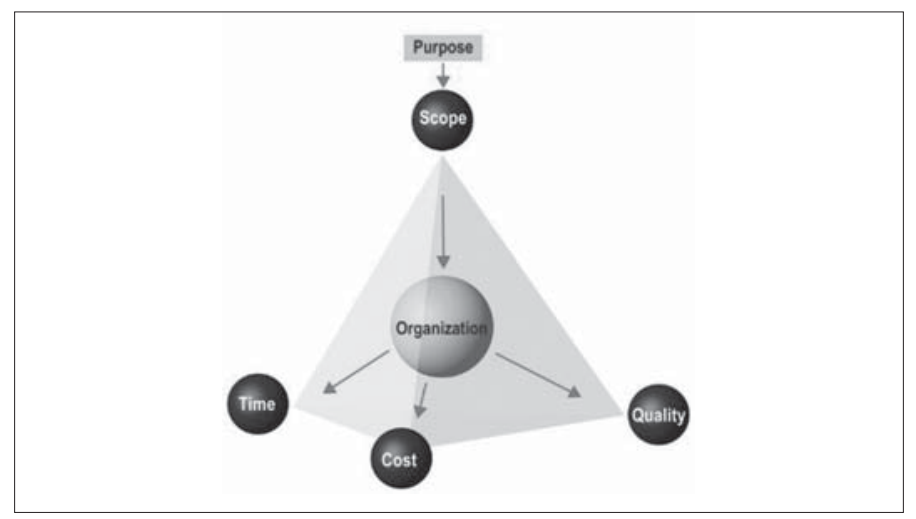

Figure 1: Factors influencing geotechnical opportunity management

participants have a common interest in exploiting these opportunities and share the risks incurred by exploiting them. To manage the site specific opportunities and risks optimally, the mutual interaction and influence of

- site specific characteristics,

- manufacturing technology and process,

- plant and equipment used for construction, and

- personnel (competence and experience)

are of critical importance (Raabe \& Warwrzyniak, 2015). These four influencing factors define a complex system of mutual dependencies in terms of technical as well as economic aspects and can offer substantial potential for optimisation, even during the initial phase of the project. This opportunity can only be exploited when there is adequate geotechnical competence involved in the initial phase of the project (interdisciplinary planning) (Schubert $\&$ Bergmair, 2002). The greatest opportunities for obtaining an optimal project design are encountered when determining the site characteristics in particular.

Different manufacturing processes, even for the same product, have different application limits that often depend on the subsoil characteristics at the site, for example for the selection of a drilling method.

The application of various ground improvement methods and the limits of their application are determined by the site characteristics. In addition to the manufacturing process, also plant and equipment can offer opportunities for an optimised design of a project, for example when using equipment offering optional, alternative methods with fast retrofitting capabilities in case such a risk actually materializes.

To facilitate a meaningful comparison of the technical and economic application of a method, all the necessary basic and boundary conditions relevant to the specific project have to be considered:

- $\quad$ surface area and volume of the ground to be improved

- type of utilisation, load application according to type, magnitude and location

- availability of materials, equipment and personnel

- availability of construction personnel with relevant technical know-how of the proposed improvement method

- influences on the environment and the neighborhood

- accessibility, ability to drive on the site in question as a function of the type of utilisation,

- environmental protection regulations (ground water, soil, air, noise).

Finally, the competence and experience of the personnel 


\section{GROUND IMPROVEMENT AS ALTERNATIVE TO PILING - EFFECTIVE DESIGN SOLUTIONS FOR HEAVILY LOADED STRUCTURES}

also play a role that should not be underestimated when dealing with the previous three influencing factors and the complex interactions between them. If opportunities are to be exploited, then they need to be recognised as such promptly, which in turn requires depth of experience.

To design a geotechnical opportunity in the interests of all partners involved in addition to the issues mentioned above, the geotechnical risk factors such as:

- (changes in the) soil conditions and properties at the site,

- technical product requirements and design methodologies,

- restrictions in the design of the plant and equipment, and

- environmental factors having an influence

should be addressed, defining the starting point for the optimisation process. Before an optimal geotechnical opportunity can be designed, it is essential to determine the site characteristics first (Gudehus, 2002). To be able to consider the widest possible range of variants and alternatives for the optimisation task, the site investigation should be designed for this purpose (depth of the boreholes, soil sampling method, soil mechanical laboratory tests). Optimal opportunity management that includes the examination of different variants (method/technologies) can naturally encompass a wider range of variants the more precisely the parameters reflect the reality at the site (Witt, 2002).

This process requires the study of alternative geotechnical solutions and their requirements on the soil mechanical parameters early on while planning the site investigation, which means that even in this phase, geotechnical expertise can open a range of opportunities. Furthermore, opportunity management is naturally controlled by the requirement of the construction task. In addition to assessing the consequences of damage in connection with the reliability index, it contains recommendations for detailed quality monitoring measures for the planning phase as well as the design phase that should be followed and used as a basis for opportunity management. If the geotechnical properties and requirements on the construction project should be brought into alignment in the next step so that a high quality, economical, and ideally scheduled solution need to be found, then geotechnical methods for solving the problem at hand should be compared to each other and potential alternatives evaluated. During this process the opportunities as well as the risk inventories of individual alternatives also need to be examined and evaluated. The most economically acceptable alternative does not necessarily have to be the one with the lowest risk inventory, and the lowest probability of occurrence may not be associated with the alternative with the lowest influence on cost, schedule and quality. To perform opportunity management in an organised manner in this complex system of geotechnical alternatives, expertise and competence in the following areas should be integrated into the project as early as possible:

- a wide range of geotechnical technologies

- the limits of application of the individual methods (technology, devices, etc.)

- the risk inventory of each method in connection with the ground conditions

- efficiency (cost) of the various methods and applications

If, for example, an excavation pit with foundation piles for the superstructure has already been designed and the superstructure design is also based on this concept, then there will only be a very small opportunity to replace the pile foundation through diaphragm wall elements when awarding the excavation pit contract.

\subsection{COMBINATION OF GEOTECHNICAL TECHNOLOGIES}

In standard design practice, a distinct gap exists between piling and Ground Improvement (GI) solutions used for foundation support. Piling is typically adopted for heavily loaded structures, such as high-rise buildings, bridges, large commercial centers, silos and other industrial objects, for which stringent bearing capacity, stability and settlement criteria must be satisfied. Conversely, GI solutions are usually considered to be of no or limited use for heavily loaded structures, mainly due to the perceived inability to limit total and differential settlements to an acceptable level.

Undoubtedly, the predominant use of piling for foundation of heavily loaded structures is reasonable and has a long tradition. It should be noted, however, there is also a range of applications where piling and GI solutions may actually overlap. This is illustrated in Figure 2, which shows tentative ranges of GI and piling solutions in a schematic load vs. settlement graph.

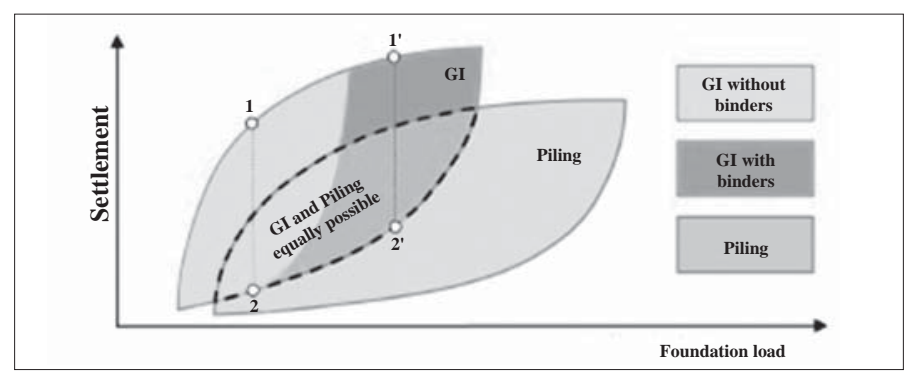

Figure 2: Tentative ranges of piling and ground improvement solutions for foundation support

For an exemplary GI design, marked as point 1, the associated settlement corresponds to a relatively susceptible foundation support. For the same foundation and loading, a significantly stiffer GI design can be also applied, for example, by increasing the area improvement ratio of the treatment. The resulting reduced settlement is represented by point 2 . Between points 1 and 2, other GI solutions exist for the same loading. Taking into account different combinations of foundations, loads and GI methods a range of possible GI solutions can be encircled by connecting a family of corresponding points ' 1 ' and ' 2 '. A complementary range of piling solutions can be drawn in a similar way. The combined figure obtained reveals an overlapping area where piling and GI solutions may both be applicable for a given range of loads without compromising functional design criteria. In this respect, it should be noted that GI solutions usually offer shorter execution times and lower construction costs, and are therefore attractive to clients and contractors. In many situations they also reduce the project's carbon footprint.

\subsection{EXAMPLES OF GEOTECHNICAL OPPORTUNITY MANAGEMENT}

\subsection{Sea Tower Gdynia}

The underlying projects involve different ground conditions, structures sensitive to total and differential settlements, and heavily loaded foundations in the form of slabs and separated footings. Densification of a loose cohesionless soil deposit by applying VC is one of the most effective GI methods. Figure 
3 illustrates the use of VC to support a high-rise building (Sea Towers) in Gdynia, constructed behind a gravity-type quay wall.

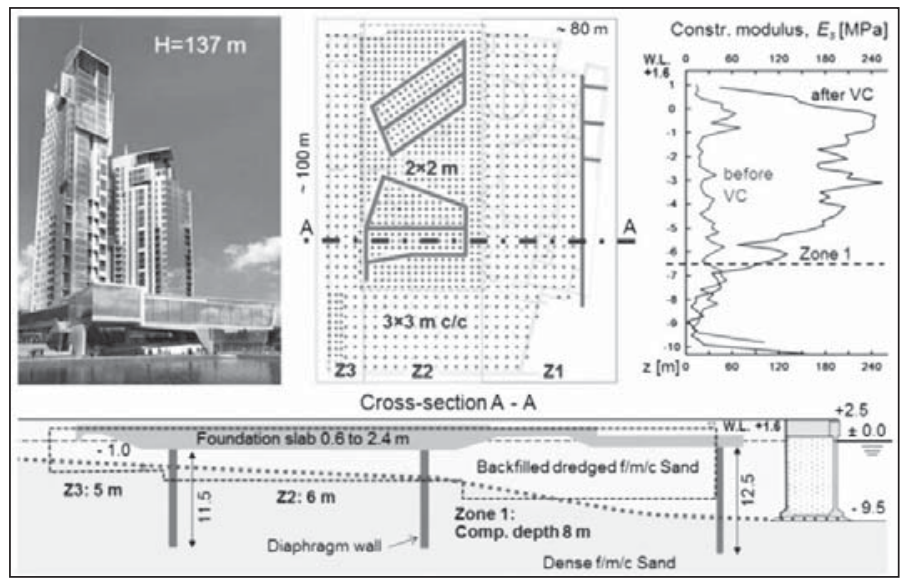

Figure 3: Compaction of dredged soil with VC to enhance slabsubgrade interaction

The area was a dredged zone of backfilled marine sediments in a loose to medium dense state, composed of fine/medium/coarse sands with some silty inclusions in deepest parts of the dredged zone. While the concentrated loads from both towers were mainly taken by purposely located diaphragm walls, the design aimed to optimise the thickness of the foundation slab utilising subgrade reaction. To increase ground stiffness below the slab, $\mathrm{VC}$ was applied to a depth of 5 to $8 \mathrm{~m}$ below the working level, and in two grids of 2 and $3 \mathrm{~m}$ $\mathrm{c} / \mathrm{c}$ spacing. A significant improvement was achieved, allowing the use of an average constrained compression modulus Es of $160 \mathrm{MPa}$ in the design. The GI design was based on FEM 3D soil-structure interaction analysis. There was a good agreement between the observed and predicted settlements (Figure 4).

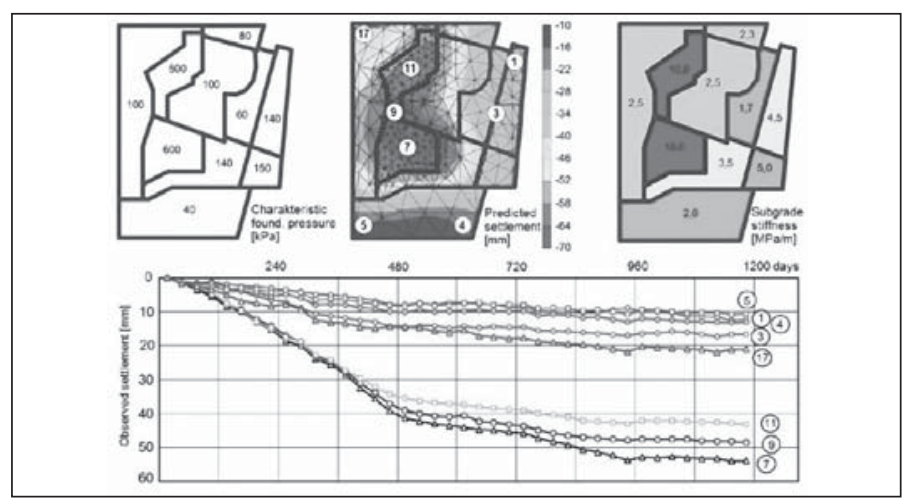

Figure 4: Predicted and observed settlements, Sea Tower foundation slab

The VC solution was an alternative to the original design, which comprised 1,312 stabilised columns $0.8 \mathrm{~m}$ in diameter and $3.5 \mathrm{~m}$ long, on average. The applied scheme was more than three times less expensive than the original solution, and also shortened the construction schedule.

\subsection{Iron Ore Storage Facility, Teluk Rubiah, Malaysia}

A large international raw material distribution organisation was building an iron ore and pellet distribution center on the north-western coast of Malaysia. The project area is located in a wide valley basin, bounded by a range of hills to the north. The distribution center will handle around 90 MTPA (million tons per annum) of iron ore and the total storage space extends about
$800 \mathrm{~m}$ north to south respectively $1400 \mathrm{~m}$ east to west and is about $200 \mathrm{~m}$ from the coastline.

The existence of soil with low bearing capability in the area designated for the plant meant that measurements to increase bearing capacity were required in the storage areas in order to reconcile the need for iron ore and pellet storage areas with requirement of the loading facilities as the overall project demand.

As a result of the soil investigation works the subsoil conditions in the stockpiling area was divided into different geotechnical zones. This split into zones A, B and C was based primarily on soil type and layer thickness. Each zone was further divided into subzones (e.g. Zones B1, B2, B3), depending on the variability of the localised soils for the subsequent geotechnical analyses. The entire construction area is underlaid by granite rock formations, which were found at depths of between 3 and $37 \mathrm{~m}$ from ground level. This resulted in different treatment zones for the construction site as shown in Figure 5.

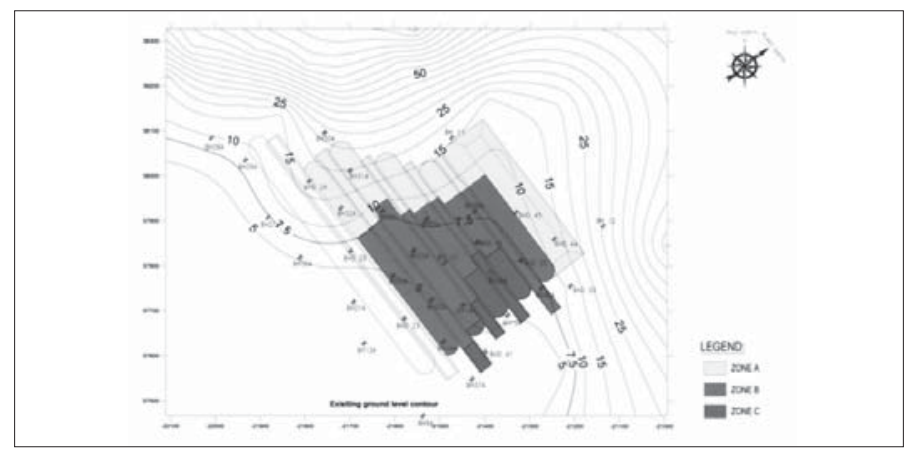

Figure 5: Geotechnical zones A, B, C and level of rock formation below ground

The loading conditions for the stockyard operations were predetermined for the design of the stockpiling areas using the following framework parameters:

- Bulk density of the iron ore is to be set at $28 \mathrm{kN} / \mathrm{m} 3$.

- Average load intensity over the entire stockpiling area approx. $375 \mathrm{kPa}$.

- Peak load in the centre line of the stockpiling area of approx. $532 \mathrm{kPa}$, corresponds to an overall height of $19 \mathrm{~m}$.

- The maximum load combination (worst case scenario) results from the maximum load of every second stockpiling strip $(1,3,5,6)$.

Long-term performance and settlement criteria were given as requirements for the foundation design and, if necessary, the ground improvement measures in order to achieve the long-term serviceability and stability behavior of the stockpile and loading systems. The criteria which should be fulfilled following the first full load were (Figure 6):

- to maintain a maximum settlement of $400 \mathrm{~mm}$, indicated in the technical conditions,

- when working out a technical solution for the soil improvement system to respect the max. lateral displacement of $10 \mathrm{~mm}$ as tolerance for the rails of the stacker- reclaimer

- and specify in the design the maximum expected horizontal displacement for the piles and the rails along the berms.

As the site conditions are characterised by very difficult geological conditions with very soft soils, along with substantially varying depth stockpiling of heavy iron ore on this kind of soil without additional measures would cause significant displacement (vertical and horizontal). When elaborating the best 


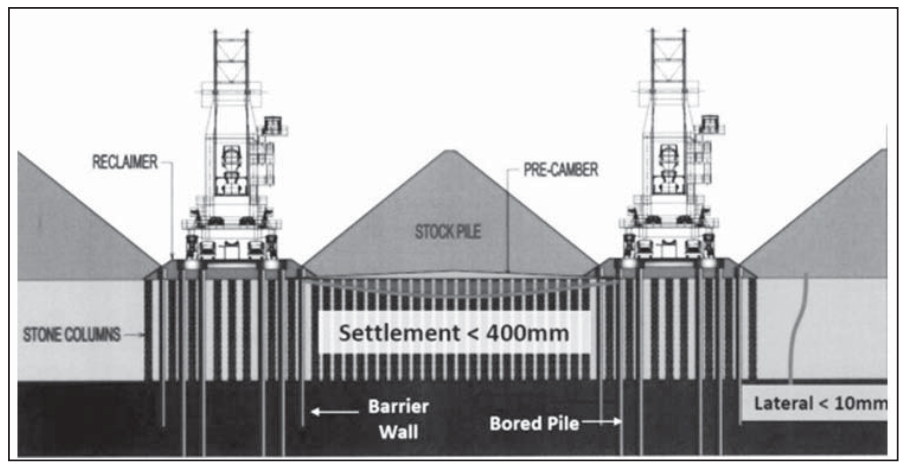

Figure 6: Deformation criteria for the design of bearing elements

solution of alternative for the Foundation/Ground Improvement from the several available options for a sustainable reduction in deformation, the following important aspects were considered:

- Technically useful - to transfer both vertical and horizontal loads while adhering to the displacement criteria

- Sustainable - the load-bearing capability does not decrease with time

- Cost effective - should take into account the economic framework;

- Feasible and easy to construct - solution should take into account the reliable technology available in the region;

- Installation procedure and time frameworks - applied technologies should not be burdened with enormous risks or investments;

- Environment - methods should not cause environmental damage to the landscape or bodies of water;

Taking these requirements and limitations into consideration, several different variants were tested:

Alternative 1 - vibro stone columns in combination with pre-cast driven piles

This basic concept incorporated the installation of vibro stone columns (Sondermann, Kirsch 2018) in the stockpiling area, over the layer thickness of the soft clay. The stackerreclaimers were founded on deep pre-cast driven piles. The analysis of this variant showed:

- Vertical movement of $240 \mathrm{~mm}$ after initial loading. The ground improvement using vibro stone columns therefore fulfilled the requirement criteria.

- Lateral displacement of $101 \mathrm{~mm}$ of the stacker-reclaimer area which exceeded the criterion. In addition, the bending moments of the pre-cast piles exceeded the capacity of the pre-cast piles.

Alternative 2 - vibro stone columns, soil stabilization, prefabricated driven piles

Like alternative 1 but using soil stabilization (DSM - deep soil mixing) in the area around the driven piles in order to reinforce the ground around the foundation piles and reduce displacement (Topolnicki M., 2013). The depth of the DSM treatment varies between $5 \mathrm{~m}$ and $10 \mathrm{~m}$. The geotechnical analysis resulted in:

- Vertical movement of $240 \mathrm{~mm}$ after initial loading.

- Lateral displacement of $55 \mathrm{~mm}$, which exceeded the criterion. In addition, the bending moments exceeded the acceptance capacity of the pre-cast piles.

Due to the risks associated with this deep mixing technology (Sondermann et al., 2013), this variant was improved by adding a higher replacement relationship of the DSM treatment using grid-adjustments, replacement of the pre-cast driven piles with $1.2 \mathrm{~m}$ diameter bored pile groups to support the stackerreclaimers; and reinforced concrete crossbeams to tie the pile caps together. The analysis of these additions resulted in:

- Vertical movement of $240 \mathrm{~mm}$ after initial loading.

- Lateral movement of $10 \mathrm{~mm}$ is satisfactory, but bending moments close to the maximum capacity.

Since the DSM technology was judged as locally underdeveloped and adequate equipment was locally not available to the extent needed to cope with the time schedule, another, more conventional alternative was sought.

Alternative 3 - vibro stone columns, bored piles, barrier bored piles

The soil stabilisation surrounding the piles of the stackerreclaimer system was replaced by a barrier wall (bored piles) around the area of the bored foundation piles. The stacker-reclaimer was founded on pairs of piles on each side, both of which were connected by a tie beam. The barrier wall, made of circular, continuous bored piles, was connected by a tie beam (Figure 7).

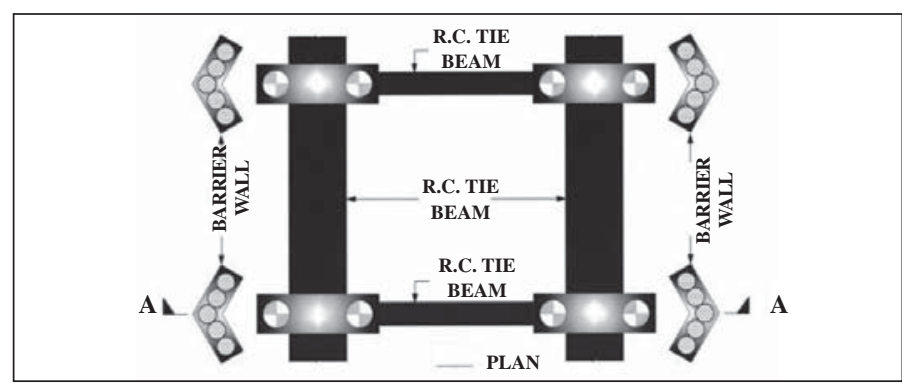

Figure 7: Alternative 3 with barrier pile walls around foundation plies and capping beams

In order to model the complex geotechnical phenomena in this layout and design, analyses using the finite element method (FEM) were carried out in zones $\mathrm{B}$ and $\mathrm{C}$ for alternative 3 . To minimize the horizontal movement of the loading system, a certain construction/ loading procedure was established which was also simulated with the FEM analysis. In this context, the extended elasto-plastic hardening model for the simulation of the soils in the current FEM analysis was used to illustrate the complex behavior of the plastic shearing and isotropic-plastic load process. For the subsequent asymmetrical loads, elastic soil behavior was expected of the zone with higher soil stiffness in the unloading-reloading area (Schanz et al., 1999). The results of the investigations for symmetrical and asymmetrical load conditions show that the stiffness of the barrier construction has a significant impact on the forces and the deformations of the foundation piles as well as on the barrier piles themselves.

In order to verify these impacts and to examine the accuracy and reliability of the 2D FEM analysis results, a complex 3D FEM analysis for zone $\mathrm{C}$ was carried out, using the most unfavorable soil conditions of soft clay with loose sand up to approx. $20 \mathrm{~m}$ below the ground surface. The soil parameters and simulation of construction sequences remain the same as for the 2D FEM analysis. Figure 8 shows the 3D FEM mesh in the event of maximum asymmetrical loading: stockpiling up to $19 \mathrm{~m}$.

The impact of stiffness and layout of the barrier wall was investigated and showed that too high stiffness in this system is leading to an increase in the diameter of the piles as well as in the amount of reinforcement. The comparison with the 2D FEM results of approx. $9.6 \mathrm{~mm}$ verified the accuracy and reliability of the $2 \mathrm{D}$ FEM and showed the effectiveness and feasibility of the proposed alternative 3 .

2D and 3D FEM analyses were also carried out for zones B and $\mathrm{C}$ and the results of the 2D FEM analysis were confirmed by the 3D FEM analyses for a critical section in zone $\mathrm{C}$, which showed easily comparable results. Essentially, the efficiency of the suggested variant depends mainly on the form and stiffness 


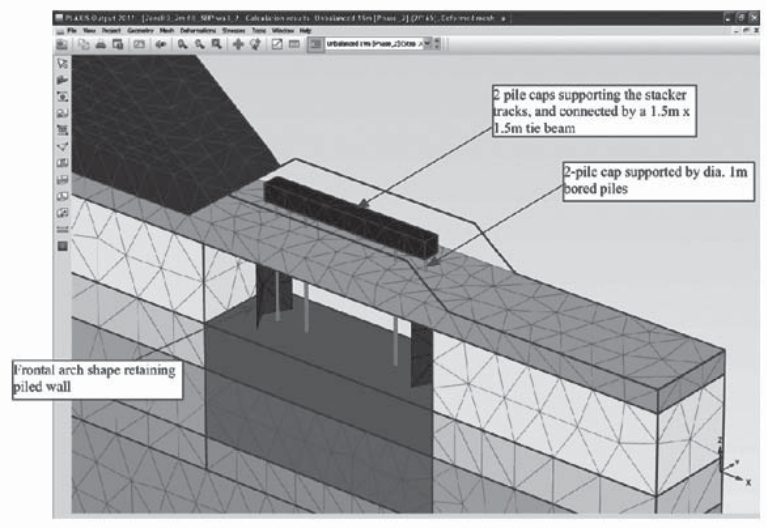

Figure 8: Spatial configuration of the barrier wall and bored piles

of the barrier construction, which produces a supporting arch effect, in order to achieve an effective minimisation of the soil movement and to minimise the effects on the horizontal load of the bored piles. Varying the diameters of the barrier piles and the depth produced an optimal load on the bored piles for the crane track. These effects were also observed by Qiu et al., (2013) in very small scale tests, where creating a bearing arch between the barrier piles diverts the horizontal load into these piles.

Because the loading sequence during the stockpiling of the iron ore material on the improved ground was crucial for successful compliance with the deformation criteria, an initial load scheme was elaborated following these design considerations. The instrumentation as an important component of the implementation of the project is based on the following principles:

- The instrumentation should allow the adoption of design and dimensioning measures to be inspected in-situ.

- The monitoring program should cover the entire stockpiling area, in order to examine the reaction of the improved subsoil under load and to take any appropriate, necessary measures.

- The monitoring data are noted and automatically stored on a server in order to be able to evaluate the data at any time, depending on operational needs.

- Communication with the operating team, if the threshold values are reached or exceeded.

The information about the soil reactions during the iron ore stockpiling process should be made available for the optimisation and management of this process. The instrumentation, with monitoring program, was installed before the first loading and was subject to regular evaluations for subsequent loading cycles for up to 2 years after the initial loading.

\subsection{Foundation for Hull Block Assembly Factory, Singapore}

A very large single-storey steel frame structure $(670 \mathrm{~m} \times 185 \mathrm{~m}$, up to $50 \mathrm{~m}$ in height) is being constructed with the structure consisting of storage area with loads up to $160 \mathrm{kPa}$ and factory area that houses heavy overhead cranes and laser cutting and welding equipment, which are very sensitive to differential settlement. The site area was reclaimed about 2-3 years prior to the foundation works. Preliminary soil investigation indicates that the site is underlain by up to $27 \mathrm{~m}$ of reclamation fill, mostly consisting of relatively clean sand, overlying original seabed. Up to $15 \mathrm{~m}$ of sandy clay was found within the reclamation fill in some area. Underneath the reclamation fill, up to $11 \mathrm{~m}$ of soft to firm marine clay was discovered at a few soil investigation locations. Extensive soil investigation was carried out once the decision of adopting ground improvement was made. The main purposes of the investigation are to obtain more information on the sub-soil condition and to identify the extent of weak soil for an optimal ground improvement design. It is revealed that a "valley" about $50 \mathrm{~m}$ wide and up to $11 \mathrm{~m}$ deep filled with marine clay runs though the foot print below reclamation fill (Figure 9).

A Cone Penetration Test (CPT) result within the area is shown in Figure 10. It is worthy to note that the marine clay layer only underlies area with relatively small load (20-50 kPa live load) as compared to the storage area (160 kPa dead load). Addition investigations disclosed the soil is under-consolidated and will continue to undergo consolidation process which result in significant settlement even if no additional load is placed.

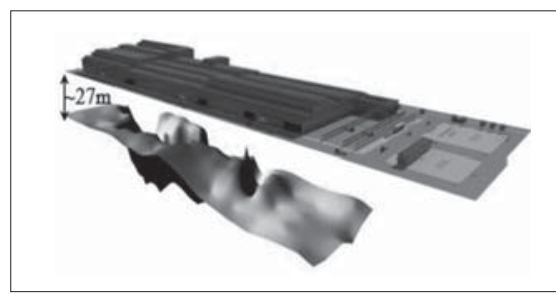

Figure 9: Underlying marine clay layer

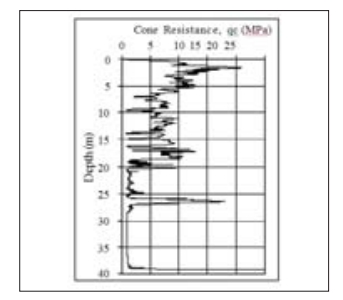

Figure 10: Typical cone penetration test result
The structure being constructed is a steel frame structure with cladding roof and façade. The structural columns are arranged in strips with about $9 \mathrm{~m}$ spacing between columns and about 20-30m between strips. These columns support the main structure as well as crane rails that span between columns along columns strips. The columns are founded on reinforced concrete ground beams of over $1 \mathrm{~m}$ thick and up to $5.8 \mathrm{~m}$ wide. Steel cutting, forming and welding equipment are installed on the factory floor, which are constructed of reinforced concrete or fibre reinforced concrete with localised enhanced reinforcement for heavy machines. The layout plan of foundation beams and slabs is shown in Figure 11.

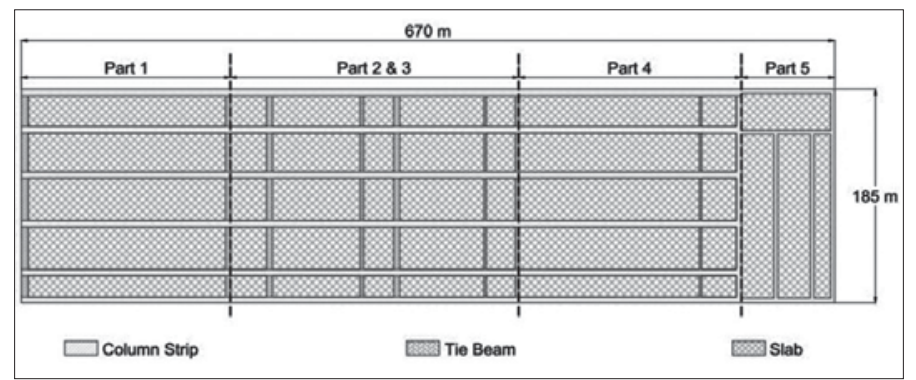

Figure 11: Foundation raft layout

The factory building is divided into four parts, which are separated by expansion joints, in accordance to its intended usage: Part 1, Part 2\&3 and Part 4 are the main factory floor area where steel cutting, forming and wielding activities will be carried out; Part 5 mainly consists of storage area where up to $2 \mathrm{~m}$ of steel plate will be stored. The foundation beams and slabs for each part are constructed as one large raft to minimise the differential settlement. Transition slabs of $1 \mathrm{~m}$ thickness are also constructed underneath expansion joints to limit the differential settlement.

\section{Foundation Solution}

Initially driven pile was considered for supporting the column strips and the slabs would be founded directly on vibro compacted ground. After 


\section{GROUND IMPROVEMENT AS ALTERNATIVE TO PILING - EFFECTIVE DESIGN SOLUTIONS FOR HEAVILY LOADED STRUCTURES}

reviewing the sub-soil conditions, it was determined that this solution was unfeasible due to the presence of the marine clay (Raju V. R. et al., 2005). The ground would continue to settle due to consolidation of the clay if it is left untreated. Significant differential settlement would occur between slabs and column strips. To cater this, both slabs and columns would have to be supported by piles, or large bored piles need to be used with slabs being suspended between column strips. Furthermore, due to the presence of thick sand layer above the consolidating clay layer, the piles would have to be designed to take considerable Negative Skin Friction (NSF), which could be greater than the structural capacity of available driven piles. In addition, piles are likely to bear more NSF if the sand is compacted, as more friction would be generated in sand layer. Therefore, piles are not effective for use under such circumstance.

Thick layer of well compacted sand on the top would provide sufficient bearing capacity and a stable platform for the structure, and pre-consolidated marine clay would not settle excessively. Accordingly, deep compaction using vibro technique is adopted to compact the sand layer and Prefabricated Vertical Drain (PVD) with surcharge is used to pre-consolidate the marine clay. The ground improvement scheme is illustrated in Figure 12.

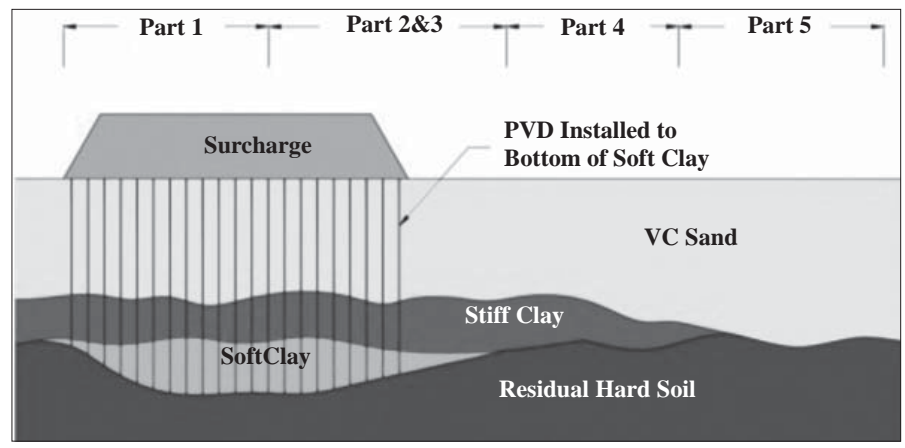

Figure 12: Ground improvement scheme

Instrumentation program is also implemented during the ground improvement work to monitor the consolidation process of marine clay. Since the marine clay is at more than $27 \mathrm{~m}$ below ground surface, deep settlement gauges (extensometer with magnetic spiders) are installed to measure the settlement within marine clay layer. The predicted and measured settlement in marine clay layer during surcharge period is shown in Figure 13. In order to ensure the required degree of consolidation is achieved at the end of surcharge, part of the surcharge was removed and the settlement is observed for about a week.

Presence of a narrow strip of thin marine clay layer with about $20 \mathrm{~m}$ width and $3-5 \mathrm{~m}$ depth was also found below $26 \mathrm{~m}$ of sand. 3-D finite element analysis was performed to evaluate whether the clay layer need to be treated. The settlement of marine clay is relatively larger than surround soils at $26 \mathrm{~m}$ below ground level. However, similar settlement contour is not reflected on the ground surface (Figure14).

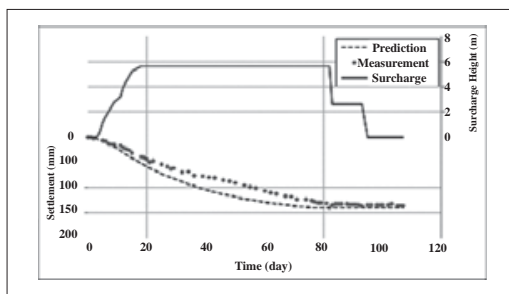

Figure 13: Settlement - surcharge period

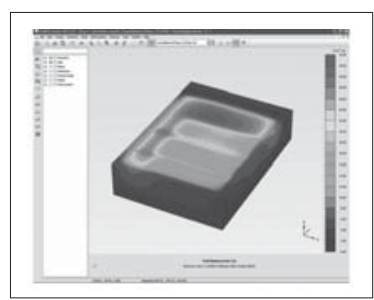

Figure 14: Long-term ground settlement contour with max. of about $36 \mathrm{~mm}$
Instead, the surface settlement corresponds more to the loading pattern rather than the shape of marine clay area. This indicates that the load from ground surface has been arched/bridged over by the stiffer vibro-compacted sand fill above the soft clay. Therefore, no treatment was applied to improve the soft clay.

\subsection{Deep Soil Mixing as Foundation of Road and Railway Viaducts}

Since 2002 more than 250 road and railway viaducts have been successfully founded on treated ground by deep soil mixing with the benefit of shorter construction times and lower costs of ground improvement with DSM contributed to substantial economical savings as compared to traditional piling technologies (Figure 15).

The selection of specific installation patterns of DSM columns requires careful attention to viaduct abutments and foundations loaded with large horizontal forces and overturning moments. Columns installed to improve the stability of foundations should be placed in single or double rows, purposely arranged with regard to critical loading schemes. This increases the system efficacy when compared to single columns, in that the negative effect of local column weakness and the risk of bending failure of the columns are reduced. Overlapping of columns in the individual rows increases bending resistance. Overturning stability can be improved through increasing the number of columns and increasing the length of rows.

Figure 16 illustrates DSM works for a typical road viaduct. The settlement of viaduct foundations supported on DSM columns can be conveniently evaluated with a simplified method, similar to that used for pile groups. For this purpose, the maximum characteristic vertical load applied on the base of the foundation is converted to a uniform pressure, and the foundation is assumed to be rigid. The total settlement is calculated as the sum of: (1) the compression of the deep mixed zone below the foundation, (2) the compression of the underlying ground, and (3) the punching of columns into the underlying soil layer at toe level.

The compression of the deep mixed zone is calculated based on the assumption of equal strains in the columns and the adjacent untreated soil within the foundation area. The compression of soil below the columns is evaluated with a load-spread method using stresses determined in the elastic isotropic half-space below a fictitious foundation assumed at columns' toe level.

Punching is especially important for columns with shallow embedment depth and for ground improvement applications with floating columns. The settlement caused by punching can only be roughly estimated when restricting calculations to sole elastic deformations. For this purpose the column base area is replaced by an equivalent square plate, which is loaded with a uniform pressure corresponding to the difference between the stress in the column at toe level and the stress acting at the base of the fictitious foundation. Since localised plastic deformations are not taken into account in this approach, the resulting settlement due to column base punching is usually smaller than one calculated with elastic-plastic models. For viaduct foundations with complex column patterns and/or loading schemes, consideration should be given to supplementing simplified settlement analyses with Finite Element (FE) computations.

\subsection{DSM as Foundation of Wind Turbines}

When soil mixing is performed to support wind turbine foundations 


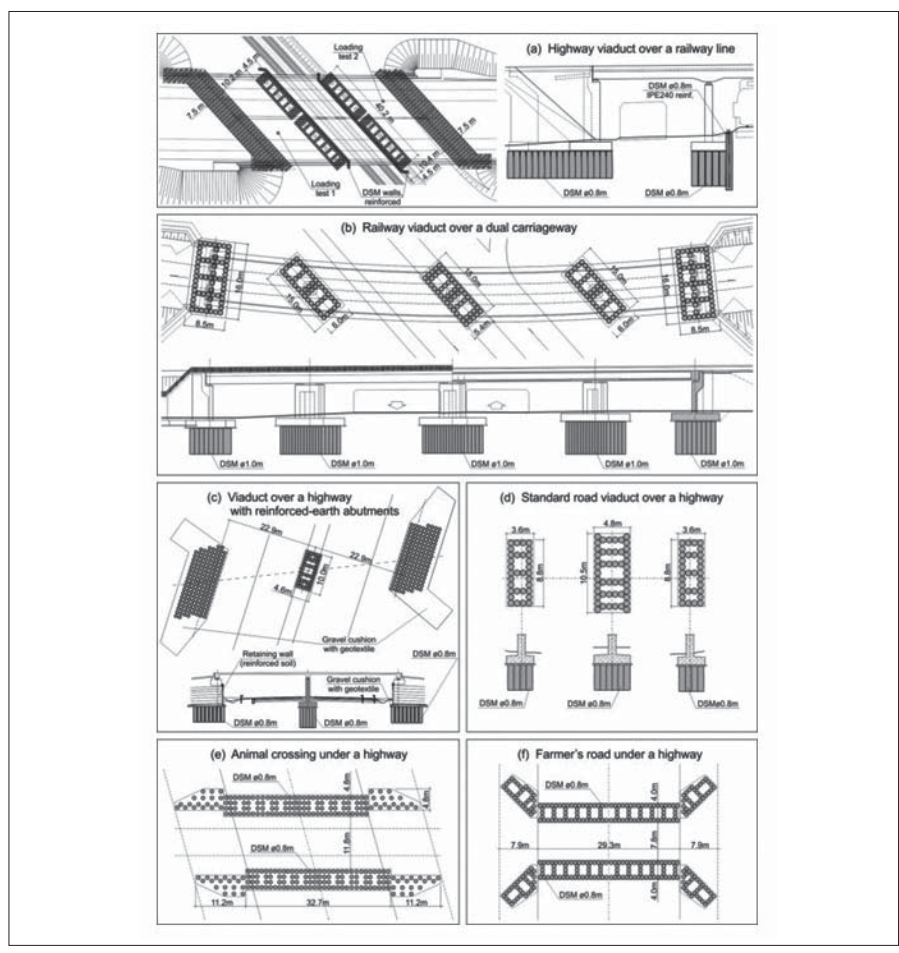

Figure 15: Installation patterns of DSM columns under foundations of viaducts
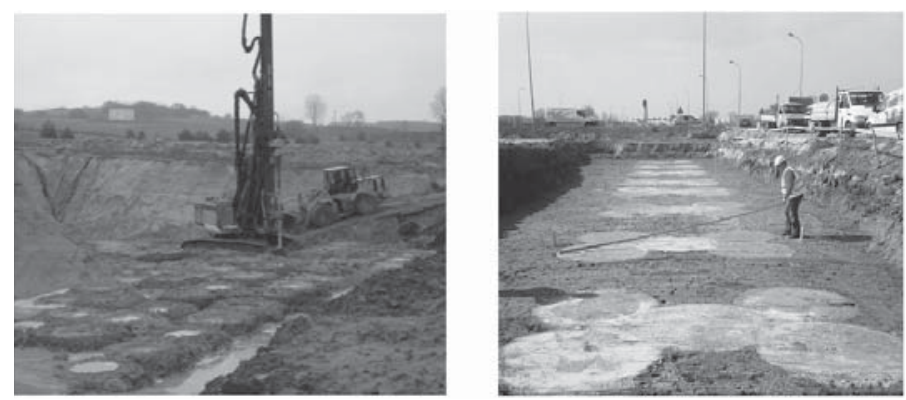

Figure 16: DSM works / exposed columns before placement of a lean concrete layer

the external loads can be transferred down to the bearing layer, resulting in a fixed type improvement, but can be also partly or wholly transferred to the foundation soil when a more interactive or even a floating type of foundation system is desired. The choice of the load transfer system adopted and of the required strength of cemented soil is dictated by functional requirements and associated design criteria.The geotechnical design of DSM is aimed to determine the final installation pattern and dimensions of improved ground on the basis of relevant Ultimate Limit States (ULS) and Serviceability Limit State (SLS) analyses to satisfy functional requirements of wind turbine manufacturers. It must be noted that the behaviour of wind turbine foundations is generally governed by a high overturning moment. Consequently, foundation tilt is of major concern as well as the overall stability of the wind turbine, which strongly depends on the position of the centre of rotation.

Depending primarily on the adopted arrangement of DSM columns and on the selected design UCS of stabilised soil, which in general may represent hard to semi-hard material, the improved ground is usually considered as a geo-composite system. Deformation and stability analyses for composite ground are often complex and involve non-linear and stress/ strain dependent interaction behaviour. Therefore simplified calculations based on semi analytical methods often need to be cross- checked or supplemented by advanced 3D FE analysis to determine more realistic foundation displacements and stresses acting in individual columns.

In practice, mainly blade-based mixing tools diameter 0.6 to $1.6 \mathrm{~m}$ and single-shaft rigs have been used to install DSM columns purposely located along the periphery of wind turbine foundation. Both, unreinforced and reinforced DSM columns have been used, as shown in Figure 17.

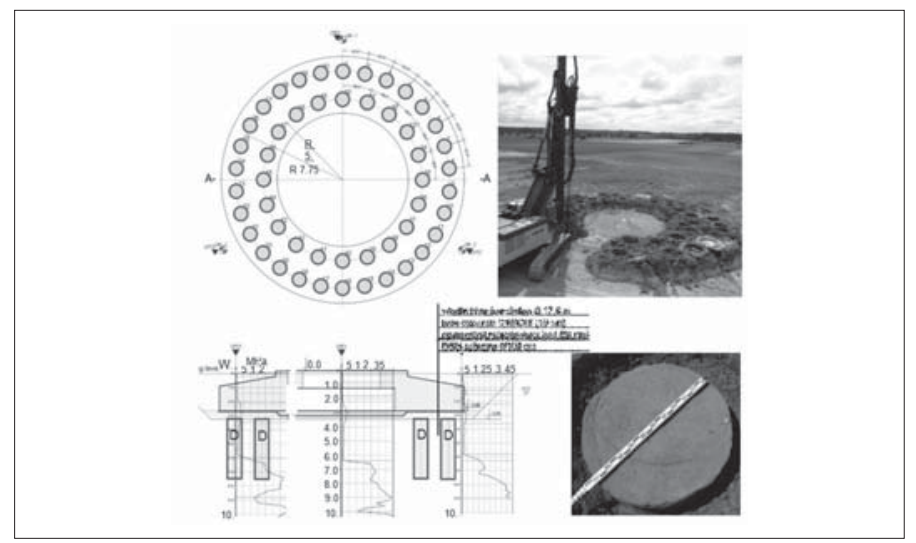

Figure 17: Wind turbine foundation supported on 50 unreinforced DSM columns diameter 1.0m (turbine height 98m)

In this case, comprising $98 \mathrm{~m}$ high wind turbine with rated power of $2 \mathrm{MW}$, the adopted solution involved 50 unreinforced DSM columns diameter $1.0 \mathrm{~m}$, arranged in two rows along the periphery of a foundation base having a diameter of $17.5 \mathrm{~m}$. To avoid stress concentrations on the trimmed heads of DSM columns, a $50 \mathrm{~cm}$ thick sand/gravel cushion has been designed, installed and compacted before application of the lean concrete layer, $10 \mathrm{~cm}$ thick. The adopted characteristic compressive strength of soil-mix was $2.3 \mathrm{MPa}$ after 56 days of curing.

The second example, presented in Figure 18, illustrates the application of 38 no. unreinforced DSM columns diameter $1.6 \mathrm{~m}$, applied for ground improvement below a circular foundation of $20.5 \mathrm{~m}$ diameter, supporting $119 \mathrm{~m}$ high wind turbine. The resulting area improvement ratio is thus $23.1 \%$. The transition layer above trimmed DSM columns, also $50 \mathrm{~cm}$ thick as in the preceding case, has been constructed using compacted aggregate or cement-stabilised soil. The adopted characteristic compressive strength of soil-mix was $2.2 \mathrm{MPa}$ after 56 days of curing.

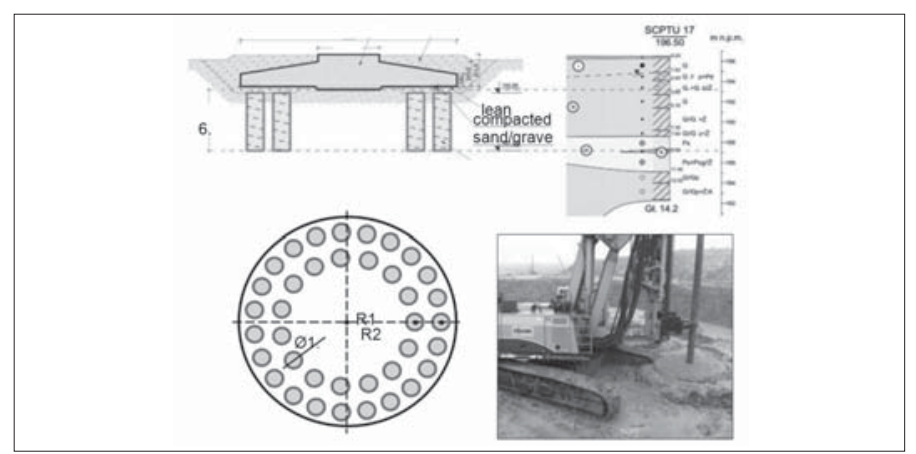

Figure 18: Wind turbine foundation supported on 38 unreinforced DSM columns diameter 1.6 m (turbine height 119 m)

When a high overturning resistance of wind turbine foundation is required, the DSM columns may be reinforced with steel beams and used in a similar way as compression and tension piles, as illustrated in Figure 19. The adopted solution comprised 40 reinforced DSM columns diameter $1.0 \mathrm{~m}$, positioned in two rows along the periphery of a 16-sided polygon foundation with an average diameter of only $15 \mathrm{~m}$. 


\section{GROUND IMPROVEMENT AS ALTERNATIVE TO PILING - EFFECTIVE DESIGN SOLUTIONS FOR HEAVILY LOADED STRUCTURES}

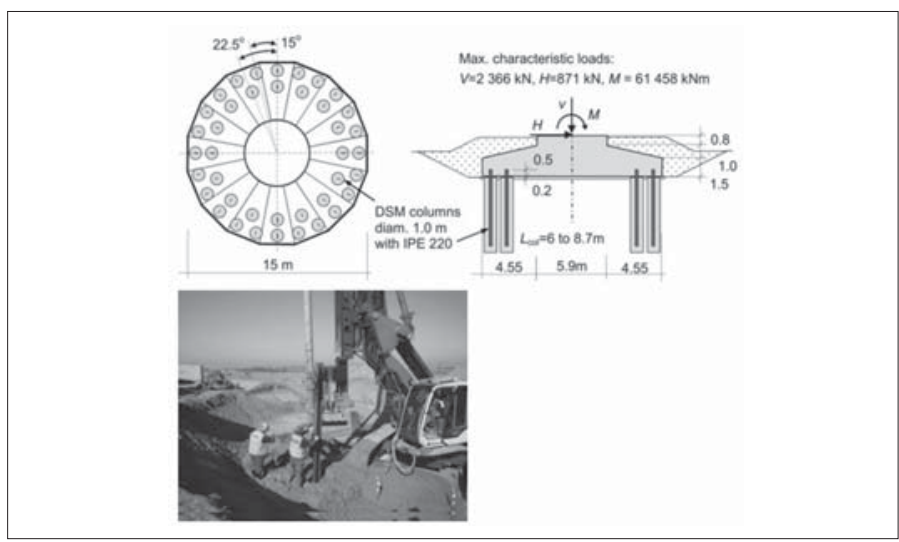

Figure 19: Wind turbine foundation supported on 40 reinforced DSM columns diameter 1.0m (turbine height $78 \mathrm{~m}$ )

Soil mixing was conducted from the bottom of shallow excavations, about $2 \mathrm{~m}$ deep. The columns, which were 6 to $8.7 \mathrm{~m}$ long depending on turbine location, were designed to take maximum compression and tension forces resulting from the adopted loading conditions. To accommodate for tension forces steel soldier profiles IPE 220, with lengths of 6 to $8 \mathrm{~m}$, were centrally installed in each column just after completion of the soil mixing operation. They extended a minimum of $0.7 \mathrm{~m}$ above the final level of column head, allowing for $0.5 \mathrm{~m}$ embedment length in the concrete foundation.

For reinforced columns bond stress of soil-mix must be checked to assure safe transfer of tensile loads to steel solider elements. Taking into account the requirements resulting from compression and tension forces acting on DSM columns, the characteristic compressive strength of soil-mix material in this project was set to $2 \mathrm{MPa}$ after 56 days of curing.

\subsection{CONCLUSIONS}

The interaction between the ground conditions and characteristics of the various homogeneous areas and technical project requirements determine the portfolio of geotechnical solutions. The determination of realistic parameters has a decisive influence in this case on the selection of potential geotechnical methods and the possible designs. The chances for obtaining an optimal geotechnical design for a project increase disproportionately as the density of the geotechnical information obtained increases. The significant challenges for the future can be summarized in the following five theses:

\section{- Construction projects are becoming more and more complex:}

In the future, the increasing complexity of projects will probably lead to significantly more attention being paid to experience in such tasks as planning, designing, calculation and execution. Only by integrating this experience into the construction process this complexity will be manageable.

- Economic optimization requirements will promote global co-operation and increasing global competition:

In the future, optimizations aimed at economic improvement will also create substantial cost pressure and will force global co-operation. These developments will lead inevitably to increasing international competition and likewise, this increasing internationalization of the market conditions will bring intensified contractual conditions and clauses with it. In order to meet this challenge, improved knowledge of contract and risk management, right from the project management level, will be essential, alongside the increasing requirement for technical capabilities.
- Increasing demand for automation and the automatic monitoring of building processes:

With increasing complexity and increasing pressure on efficiency, automation and the automatic monitoring of building processes will become increasingly important in order to maintain the require standard of quality. Minimizing risks of faults and bridging any gaps in experience as necessary, in order to avoid negative consequences, will be a significant task for the future. In the future, automation will create new requirements, on device manufacturers and suppliers in particular, to directly and promptly optimize productivity and quality using improved, process-oriented monitoring in the construction process.

- Clients and site supervisors will expect a more efficient documentation of the processes and quality:

Increasing requirements of the documentation of construction processes will lead inevitably to improvements in existing quality and risk management systems and be developed parallel to the requirements for automation. An even closer cooperation between users and manufacturers of construction equipment should in most cases be adapted to these future tasks for process cycle documentation using measuring and sensor technology.

\section{- Environmentally-friendly technologies are becoming} more attractive:

The development and advancement of resource-saving technologies and building processes will become a significant challenge for the entire building industry, but particularly for geo-technology. Alongside the reduction in the consumption of materials and of emissions (noise, dust, vibration...), the reduction of $\mathrm{CO}_{2}$ emissions and also the improvement of the logistics process will be at the forefront.

Innovative solutions in use of new or improved technologies as well as the changing and adjusting of existing technologies to suit the specific requirements of the project can contribute to generating an increase in value for the owner. These approaches can also play their part in meeting the future challenges to reduce complexity, to increase quality through automation and documentation as well as to strengthen the global competitiveness.

\subsection{RECOMMENDATIONS}

Considering the future challenges as general requirements for changes innovative solutions could show a way out of this problematic issues. But innovative alternative solutions require a more precise management of alternative opportunities. Optimal opportunity management largely depends on the information density and the expertise of the project members and also has a permanent effect on the success of the project. Opportunity management gives the chance to achieve the project scopes for the client by optimizing cost, time and quality. The following recommendations should foster the chance to identify optimal geotechnical solutions:

\section{- Early high quality and extensive investigation on site}

A good and comprehensive investigation of the soil at the site can point out opportunities for the use of alternative processes and methods regardless of the geotechnical problem at hand. Consolidating the knowledge gained later on often fails due to limited time. The supposedly minor economic disadvantages of performing a comprehensive soil investigation at the site are compensated for over the course of the project in almost all cases through optimized opportunity management. 


\section{- Design of the alternatives using high quality methods}

A detailed examination of alternative geotechnical solutions using higher quality design methods and stress strain laws generally leads to savings during construction in time as well as in costs and improve quality in addition.

\section{- Detailed planning as part of the planning process}

The purpose of creating a project plan ready for implementation is to ensure all conditions relating to the feasibility of construction (accessibility, equipment and plant, material logistics, environmental influences and degradation, etc.) are checked in detail, and thus ensure the risks resulting from them are minimized, in order to optimally take advantage of the opportunities available.

\section{- Consideration of experience and expertise of people involved in the project}

Optimal opportunity management thrives off the opportunities that are recognized as early as possible in the project life cycle (Van Staveren M. 2013), which depends substantially on the level of expertise and experience of the engineers involved and available. For this reason, soft skills should not be ignored when selecting the participants in the project.

\section{- Early specification of the optimization objectives}

Clearly defined priorities during the decision-making process have a major influence on the ability to exploit opportunities, and changing optimization objectives or priorities as the project progresses generally lead to substantial disruptions and higher project risk.

\section{- Transparent project information system including risk and opportunity registers}

A project information system can substantially minimize the risks resulting from misinformation, especially when the tasks are complex. A transparent information system accessible to all participants, including a risk and opportunity register makes a permanent contribution to the success of an opportunity management system.

For geotechnical engineers the main future challenges are to be familiar with theoretical as well as practical applications of advanced technologies to identify for a specific project the optimal combination of technologies including the best design approach to stay competitive.

To cope with this more general and conceptual formulation of the task the below summarised capabilities and competences of geotechnical engineers to create optimal geotechnical solutions are required:

\section{Technical Skills:}

- deep knowledge of technologies and processes including the limits of application of the different technics

- excellent judgement on subsoil characteristics and stress strain relationships of soil materials

- advanced design capabilities including judgement regarding application of design model and approach

- understanding the execution process and the impact of the process on adjacent structures and the environment

- fair judgement on technical requirements versus products involved including alternatives

To cope with these requirements in addition to the technical skills geotechnical engineers should show capabilities in:
- Accuracy and reliability

- Team work and relationship with colleagues

to identify optimal solutions with the teams from different disciplines involved in a project. Those geotechnical engineers developing a sound and perfect combination of the technical expertise and the soft competences will be fit for future challenges. As a geotechnical engineer is should be the goal not only to sharpen the geotechnical knowledge but also acquire and shape interpersonal skills.

\section{REFERENCES}

[1] Ahmed S. M. (2001): Measurement of Construction Processes for Continuous Improvement. Ed: State of Florida, Department of Community Affairs, 2001.

[2] Gudehus G. (2002): Geotechnisches Risikomanagement aus bodenmechanischer Sicht (Geotechnical Risk Management from a Soil Mechanics Perspective). Proceedings of the 12th DanubeEuropean Conference in Passau, pp. 21-29, 2002.

[3] Raabe E.-W., Wawrzyniak C. (2015): Chancen und Risiken der Vertragsgestaltung für geotechnische Leistungen, (Opportunities and Risks of Contract Designs for Geotechnical Services), Bautechnik 92 (2015), pp. 624-630, 2015.

[4] Schubert P., Bergmair M. (2002): Geotechnische Risikobewertung und Risikomanagement - Methodologie und Fallbeispiele (Geotechnical Risk Evaluation and Risk Management - Methodology and Case Histories), Felsbau 20 No. 5, p. 31ff, 2002.

[5] Van Staveren M. (2013): International State of the Art Report on Integration of Geotechnical Risk Management and Project Risk Management, Part 1- Report, ISSMGE TC 304 - Task Force 3, 2013.

[6] Witt K.-J. (2002): Das Baugrundrisiko aus geotechnischer und vertragsrechtlicher Sicht (Foundation Risks from a Geotechnical and Contractual Perspective). "Damage Cases" seminar of the German Association of Road and Transport Engineers (VSVI), November 2002.

[7] Topolnicki, M. (2013): In-situ soil mixing, in Ground improvement, 3.Edition, edited by K. Kirsch, A. Bell, CRC press Taylor \& Francis group, p.329-434.

[8] Qiu, G., Reimann, K., Grabe, J. 2013: Zur Reduktion des aktiven Erddrucks infolge Verdübelung mittels Pfählen, Pfahl-Symposium Braunschweig 2013, report from the Institut für Grundbau und Bodenmechanik Technische Universität Braunschweig (Institute for Soil Mechanics and Geotechnical Engineering Technical University of Brunswick) Volume 96 pp. 327-337, 2013.

[9] Raju,V.R., Sondermann,W. 2005: Ground improvement using vibro techniques in ground improvement case histories, Indraratna, B \& Chu, J. (eds.), pp. 601-638, 2005.

[10] Schanz, T., Vermeer, P.A. 1999: The hardening soil model - formulation and verification, Brinkgreve, R. (ed.) Beyond 2000 computational geotechniques, Rotterdam, Balkema, pp. 281-296, 1999.

[11] Sondermann, W., Kirsch, F. 2018: Baugrundverbesserung in Grundbautaschenbuch, 8. Auflage, Teil 2, Witt K.-J. (editor) Ernst \& Sohn, Berlin, 2018.

[12] Sondermann, W. et al., 2013: Design risks of ground improvement methods including rigid inclusions, Proceedings 18th South East Asian Geotechnical Conference, Singapore 29-30 May 2013.

\section{Soft Skills:}

- Planning and organising

- Analysing and structuring 


\title{
THE TWENTY EIGHTH PROFESSOR CHIN FUNG KEE MEMORIAL LECTURE
}

\author{
Presented at the Auditorium Tan Sri Prof. Chin Fung Kee, \\ Wisma IEM, Jalan Selangor, 46200 Petaling Jaya, Selangor, Malaysia \\ on 10th November 2018
}

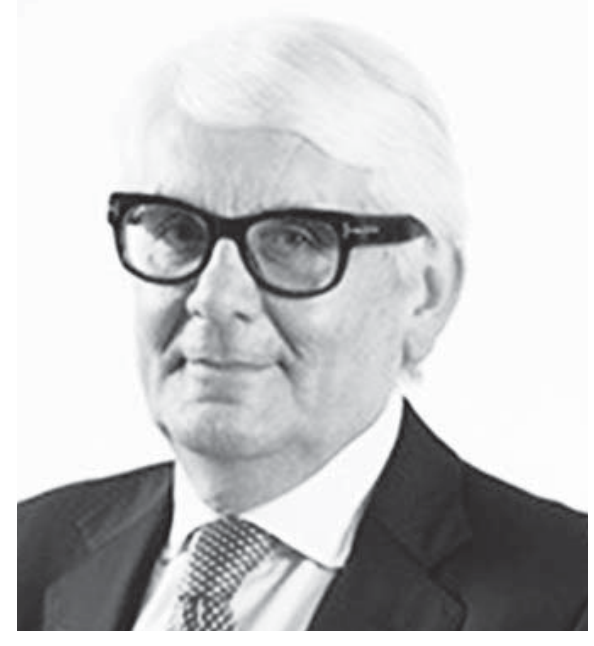

Dr Ing. Wolfgang Sondermann Consulting Engineer; Chairman German Geotechnical Society (DGGT), Essen, Germany

Dr Ing. Wolfgang Sondermann received his "Diplom-Ingenieur" on the area of expertise in structural analysis, solid construction and geotechnique from Technische Universität Braunschweig (Germany) in year 1976. He was then appointed as the design engineer and project manager for Ph. Holzmann AG, Frankfurt, based in central technical department at headquarters, working on different civil engineering projects in Germany and abroad (KSA, Libya, Iran etc.). In year 1980, Dr Ing. Wolfgang Sondermann did his PhD in "Stresses and Deformation of Reinforced Earth Structures" at Technische Universität Braunschweig (Germany) under Prof. Dr Ing. Hanns Simons, and he received his $\mathrm{PhD}$ title in year 1983.

His career further expanded when he joined as Partner and Managing Director of Geotechnical Consultants Simons \& Partner $\mathrm{GmbH}$. He was involved as the Consultant for different projects in Germany and abroad, i.e. nuclear reconditioning plant in Gorleben and Dragahn, mining plant for final storage of nuclear waste Gorbelen, cement factory in Iraq. He also introduced Tensar geogrid for reinforced earth structures, consulting activities in geotechnical problems on different environmental projects as Münchehagen, Malsch etc.

In year 1986, he joined Keller Grundbau GmbH and was attached to central technical department, mainly to support in the introduction of Soilcrete. Subsequently, he was also involved in different environmental projects and development of insitu treatment of contaminated subsoil. In year 1990, he was promoted to be the branch manager of Northern branch in Germany, managing growth in Eastern Germany after reunification and since year 1994, he extended these activities in Eastern Europe as well.
Dr Ing. Wolfgang Sondermann became the Managing Director of Keller Grundbau GmbH in year 1998, where he was responsible for all activities in Germany. In year 2000, he was then promoted to be the Managing Director of Keller Holding GmbH. He covered operational responsibility for Continental Europe, Middle East including Africa-Asian activities (CEMEA) in business development and introduction of advanced technologies and methods. In year 2003, he moved to Keller Group plc., London and became the Board Member. He was the Executive Director responsibility for CEMEA Division and later the Executive Director for Group Engineering \& Operation, before he retired in year 2016. Since then, he is acting as Consulting Engineer Geotechnical engineering and operations.

Besides, he was also a lecturer at Technische Universität Darmstadt (since 2002), Chairman of friend's association of Geotechnical Institute Technical University Darmstadt (since 2006), and Chairman of the Board of the German Society of Geotechniques (since 2014).

Dr Ing. Wolfgang Sondermann had published his works (>100 publications) in national and international magazines on geotechnical engineering, risk management, new technologies and methods. He also contributed to the Geotechnical Engineering Handbook, Vol. 2, 8. Ed.: Ground Improvement Editor: K. Witt, Ernst \& Sohn, 2016, the Ground Improvement, 3. Ed.: Ground Improvement, Editors: K. Kirsch, A. Bell, CRC Press, 2013, and the Asian Ground Improvement Handbook. In addition, he is the holder on different patents of inventions regarding geotechnical applications and devices. 